\title{
On-Site Nuclear Fuel Cycle of "BREST" Reactors
}

\section{Andrei Gennadevich Glazov, Yury Sergeevich Khomyakov, Maksim Konstantinovich Gorbachev, Leonid Petrovich Sukhanov}

Institution "Innovation and Technology Center by "PRORYV" Project", State Atomic Energy Corporation "Rosatom”, Moscow, the Russian Federation

\section{Email address:}

gag@proryv2020.ru (A. G. Glazov), hus@proryv2020.ru (Y. S. Khomyakov), gmk@ proryv2020.ru (M. K. Gorbachev), sulp@proryv2020.ru (L. P. Sukhanov)

\section{To cite this article:}

Andrei Gennadevich Glazov, Yury Sergeevich Khomyakov, Maksim Konstantinovich Gorbachev, Leonid Petrovich Sukhanov. On-Site Nuclear Fuel Cycle of “BREST” Reactors. International Journal of Energy and Power Engineering. Vol. 7, No. 1, 2018 , pp. 1-5. doi: $10.11648 /$ j.ijepe.20180701.11

Received: October 23, 2017; Accepted: December 19, 2017; Published: February 1, 2018

\begin{abstract}
Dynamic developing of modern nuclear industry demands meeting the following requirements: improved safety, reduced capital costs, radioactive waste (RW) management issues, independence of limited resources. Efficiency of uranium resources used in "BREST" reactors based on a closed fuel cycle is about 160 times higher than for VVER, RBMK reactors [1], which makes it possible to stop searching for new deposits and uranium mining. The need for periodical fuel regeneration and fabrication in a closed cycle includes reproduction of plutonium in the core without the uranium containing screens (breeding ratio is approximately 1,05 , ensuring a high level of safety and support of the non-proliferation regime) and transmutation of the most dangerous long-lived actinides and high refining of RW, achieving the radiation balance of buried RW and extracted uranium ore. The manufacturing is located directly at the NPP to avoid transportation of fissile materials. This approach provides economic efficiency of the entire complex.
\end{abstract}

Keywords: Closed Nuclear Fuel Cycle, Nuclear Energy, Fast Reactor

\section{Introduction}

This paper presents a brief description of the "BREST" fast reactor closed fuel cycle concept from the viewpoint of its specifics and ability to meet the requirements for efficiency, non-proliferation of nuclear materials and to establish a balance between generated RW and mined natural uranium [1], [2], [3], [4], [5].

\section{The Advantages of the "BREST" Fast Reactor Fuel Cycle}

The advantages of the "BREST" fast reactor fuel cycle are:

1. The possibility of sufficient increase of large-scale nuclear power rate in comparison with the current level;

2. The reduction of NPP construction capital costs;

3. Increasing safety and security level;

4. Fuel resources change - independence of natural uranium;

5. The solution of spent fuel and RW build-up issues;

6. Risk reduction of nuclear materials proliferation.

\section{Basic Parameters of the BREST-OD-300 Fuel Cycle}

The BREST-OD-300 fast reactor does not need enriched uranium for operation in the equilibrium regime, i.e. enrichment services may be curtailed and then given up with time in case of large-scale implementation of fast reactors in the structure of nuclear power industry. Civil-grade $\mathrm{Pu}$ and spent fuel will be gradually removed from existing storage facilities and spent fuel cooling pools at NPPs to be used for fabrication of the first cores for fast reactors (spent fuel reprocessed to recover $\mathrm{Pu}$ ). Initial recovery of $\mathrm{Pu}$ and fabrication of the first cores for fast reactors should be carried out at safeguarded facilities in nuclear countries under the IAEA control.

Due to the equilibrium regime of fuel burning with the breeding ratio of the core $(\mathrm{CBR}) \sim 1$ the reactivity changes between refueling (annual company up to 300 days eff are 
comparable with $\beta_{\text {eff }}$ ).

The potential utilization of highly heat-conductive dense nitride fuel in the BREST-OD-300 fast reactor $(\lambda \approx 20$ $\mathrm{W} / \mathrm{m} \cdot \mathrm{K}$ ) with liquid metal sublayer also makes it possible to decrease thermal and capacity effects of reactivity. Combined with low burn-up effect, this provides the capability of reactor operation with maximum reactivity margin that is comparable with $\beta_{\text {eff }}[6]$, [7], [8].

The operation with low reactivity margin makes the RIA impossible due to uncontrolled reactor run-out because of accidental control rods withdrawal, of staff error.

The fast reactor fuel cycle promises virtually unlimited expansion of the fuel resources available to the nuclear power industry due to processing and recycling of U-Pu-Minor actinides (MA) fuel of equilibrium composition $(\mathrm{CBR} \sim 1,05)$ which will require addition of depleted or natural uranium in the amount enough to compensate separated fission products.

The fuel cycle arrangement with complete utilization of MA allows attaining the radiation and migration equivalence between RW (with allowance made for their migration) and nuclear materials. To this end, the radioactivity and the nuclide composition of the waste subject to burial should be such that the heat and the stability of the buried materials and the degree of their respective biological hazards, taking into account the migration of the nuclides, should be at least not worse than those found at natural uranium deposits.

Design premises for the fuel cycle of the BREST-OD-300 fast reactor [9]:

1. Periodic fuel reprocessing and production of refabricated fuel in a closed cycle with low storage time after irradiation;

2. Full $\mathrm{Pu}$ reproduction in the core without $\mathrm{U}$ blankets and with the breeding ratio $\sim 1,05$;

3. Profound refining of RW to remove the actinides (not more than $0,1 \%$ );

4. Transmutation of long-lived MA (Am, Np), long storage of $\mathrm{Cm}$ and its future utilizing in the fuel cycle together with daughter fission products;

5. Radiation and migration equivalence between buried RW and uranium mined from earth;

6. Fuel facilities in the closed fuel cycle should be unsuitable for $\mathrm{Pu}$ recovery from spent fuel (technological support to non-proliferation);

7. On-site fuel facilities to avoid shipment of large amounts of high-level radioactive and fissile materials;

8. Cost-effectiveness of the fuel cycle at least equal to the cost-effectiveness of the open fuel cycle.

\section{Stages of the BREST-OD-300 Reactor Fuel Cycle}

The BREST-OD-300 fuel cycle consists of the stages usually included in the closed fuel cycle of fast reactors, except for the fuel cycle of breeding blankets:
1. In-pile fuel irradiation (5-7 years);

2. Post-irradiation cooling (1 year) of spent fuel assemblies (SFA);

3. SFA transportation to the on-site nuclear fuel cycle (SNFC) building;

4. SFA cutting to extract fuel and separate steel components;

5. Radiochemical treatment of fuel (reprocessing);

6. Adjustment of fuel composition;

7. Fabrication of nitride pellets;

8. Fabrication of fuel rods and fuel assemblies;

9. Temporary storage of fuel assemblies;

10. Fuel assembly transportation to reactor;

11. Radioactive waste management (collection, classification, air-conditioning with transferring into the form corresponding to the acceptance criteria of the national operator for radioactive waste management);

12. Intermediate storage and transmission of conditioned RW to the national operator for disposal.

\section{Brief Description of the Technological Scheme}

The scheme of the closed fuel cycle of fast reactors is shown in Figure 1.

The fuel fabrication complex includes the following main production lines:

1. The carbothermal synthesis of nitride mixed uranium and plutonium line;

2. The tabletting nitride mixed uranium-plutonium fuel line;

3. The fuel rods assembly line;

4. The fuel assembly line.

The full cycle of processing BREST-OD-300 spent nuclear fuel is implemented within the complex of spent fuel reprocessing and includes the following systems and technological areas:

1. Head operations section;

2. Spent fuel pyrochemical reprocessing section (after pre-development of the technology and equipment in the condition of the experimental pyrochemical section within the processing unit);

3. Hydrometallurgical processing of spent nuclear fuel section;

4. High-level waste treatment section.

In addition to the main technological sections the following will be included as part of the processing unit:

1. Analytical laboratory;

2. Central gas purification system;

3. Storage and chemicals preparation system;

4. System of collecting spent decontamination solutions;

5. Section of the processing unit defect treatment;

6. Section of fissile material rinse, repair and decontamination equipment;

7. Engineering support system. 


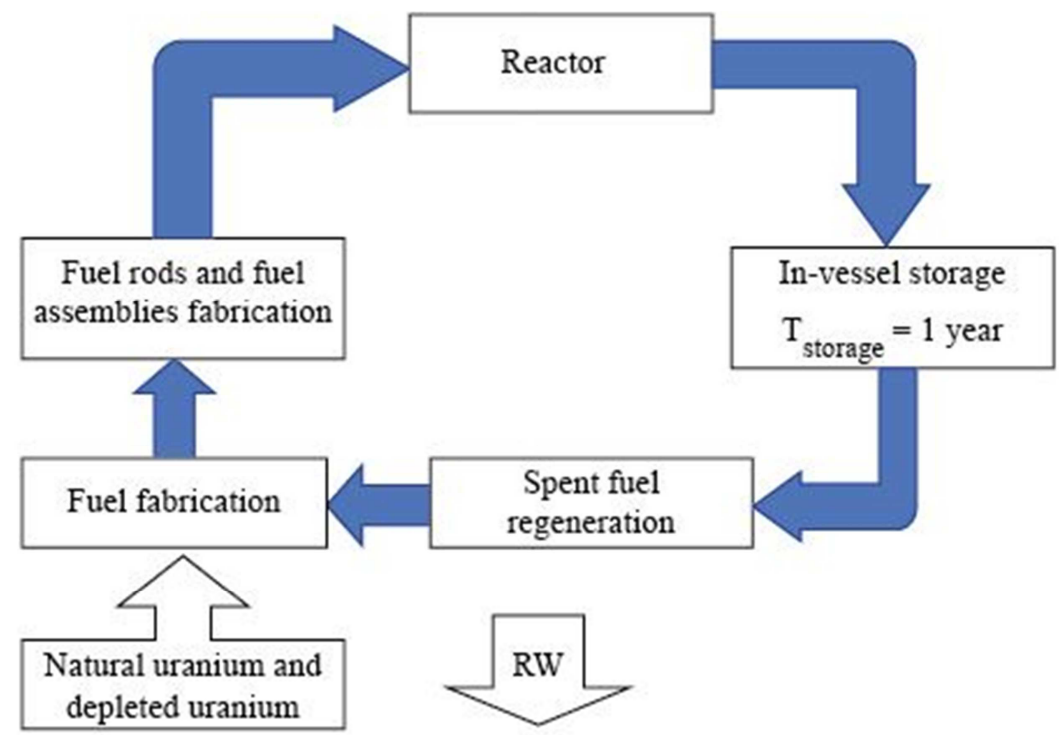

Figure 1. Closed fuel cycle scheme of fast reactors.

\section{Achieving Radiation and Migration Equivalence}

Plutonium and americium are the main sources of potential long-term biological hazards of spent fuel. Radiation equivalence may be achieved by implementing transmutation nuclear power fuel cycle having the following basic elements:

1. Processing of the total volume of spent fuel of thermal reactors with a given fractionation for transferring plutonium, MA and long-lived fission products into fast reactor fuel cycle;

2. Fast reactors working in a closed fuel cycle which burn basic actinide quantity ( $\mathrm{U}, \mathrm{Pu}, \mathrm{Am}, \mathrm{Np}, \mathrm{Cm})$ and transmute the long-lived fission products (Tc, I) in the process of power generation; sufficiently profound refining of RW which are going to be disposed from $\mathrm{Pu}$, Am and other long-lived nuclides (loss of actinides in RW is not more than $0,1-0,01 \%$ );

3. Interim storage of high-level waste prior to final disposal in order to reduce their biological hazards.

It is also desirable to introduce a new uranium mining technology that does not pollute the environment and provides joint extraction of radium and thorium from natural uranium deposits accompanying radium and thorium for further transmutation in the fast reactors' fuel (Figure 2, [2]).

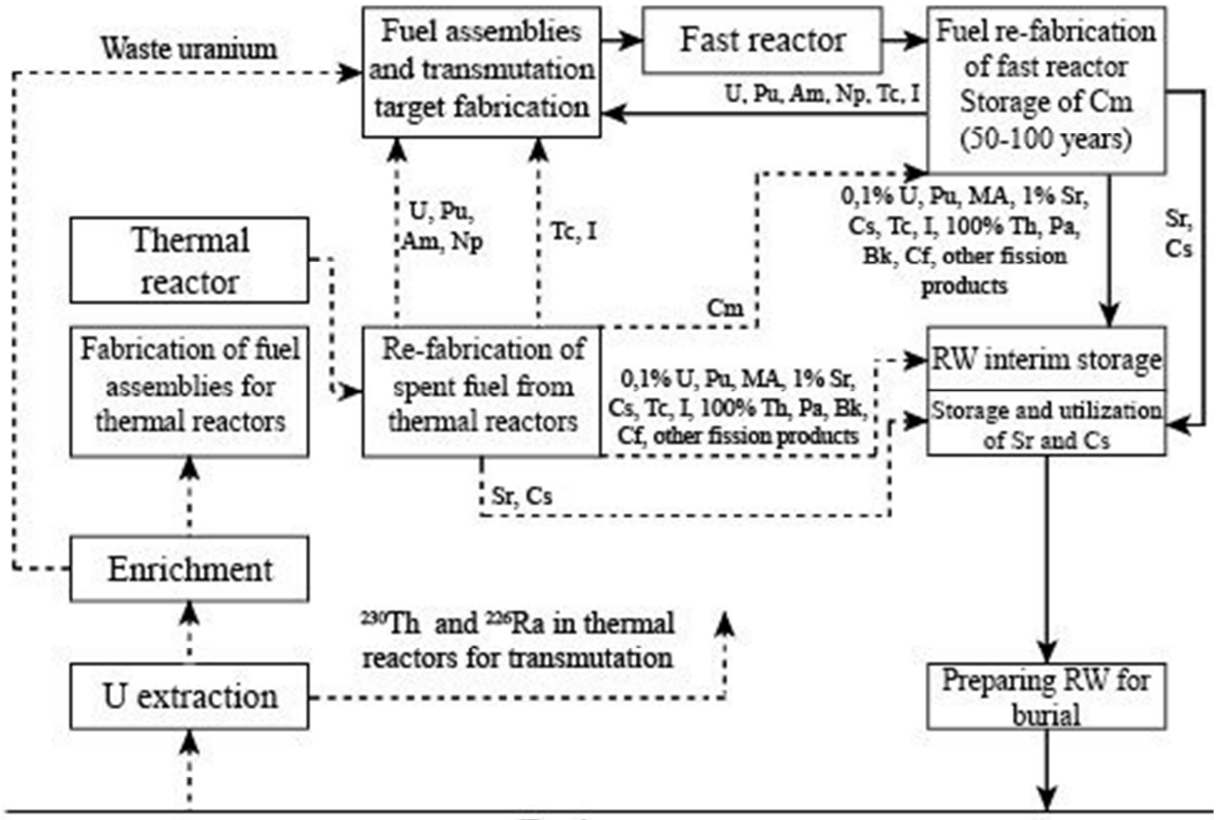

Earth

Radiotoxity of spent uranium $=$ Radiotoxity of burial long-lived RW

Figure 2. Joint nuclear fuel cycle of thermal and fast reactors. 


\section{Contribution to Non-Proliferation of Nuclear Materials}

The non-proliferation condition for the closed U-Pu cycle will be fulfilled, if the spent fuel reprocessing technology is unsuitable for separating $\mathrm{U}$ and $\mathrm{Pu}$ (i.e. separation of actinide blend with high concentration of $\mathrm{Pu}$ into an independent fraction) during all the stages of reprocessing.

Non-separation of $\mathrm{U}$ and $\mathrm{Pu}$ during fuel reprocessing must be guaranteed by the very character of the processes, as well as by the utilized equipment, and the technology must be self-protected.

It should be emphasized that only improving the international political non-proliferation regime, as well as respective control, protection and enforcement measures can prevent the danger of nuclear weapon proliferation. The implementation of a nuclear technology, not recovering $\mathrm{Pu}$ (and ${ }^{233} \mathrm{U}$ ) and not requiring uranium enrichment, allows solving this task for large-scale nuclear power.

\section{Fuel Reprocessing for "BREST" Reactors}

Reviewed spent fuel reprocessing technologies:

1. Molten chloride salts electrolysis, including actinides regeneration to metal on a solid-state cathode;

2. Metallurgical processing without disrupting nitrides on all the stages of reprocessing;

3. The technology with PUREX-process elements;

4. Reprocessing in molten fluoride salts with chemical reduction of actinides to metals;

5. Restructuring of nitrides by the reactions of nitriding and denitriding. Restructuring in molten molybdates and phosphates;

6. Variations of gas fluoride technology with high-temperature fluorination;

7. Gas fluoride technology with low-temperature fluorination;

8. Molten fluoride salts electrolysis;

9. The extraction by liquid metals of $\mathrm{U}$ and $\mathrm{Pu}$ from fluoride salts and plasma separation of MA from rare earth elements;

10. Plasma refining of actinides from fission products;

11. Electrolytic dissolution of nitrides in molten chloride salts, continued by reduction to nitrides - LINEX-process;

12. Molten chloride salts electrolysis, including actinides' regeneration to metal on a liquid cathode;

13. Reprocessing with using different solvents.

The chosen spent fuel reprocessing technologies:

Molten chloride salts electrolysis, including actinides regeneration to metal on a solid-state cathode together with the water technology with organic extraction agents [10], [11].

Table 1. Specification of fuel reprocessing for future utilization in "BREST" reactors.

\begin{tabular}{l} 
Specification \\
\hline Primary product \\
RW refining from actinides \\
End product \\
Actinides content in separated fractions of $\mathrm{Sr}, \mathrm{Cs}, \mathrm{I}, \mathrm{Tc}$ should not exceed: \\
Extracting Np from fuel: \\
Extracting $\mathrm{Cm}$ from fuel:
\end{tabular}

Description
Nitride $\mathrm{U}-\mathrm{Pu}-\mathrm{MA}$ fuel, $\sim 9 \%$ of fission products, $\mathrm{U}$ and $\mathrm{Pu}$ are not separated
Residuum $<0,1 \%$
Metal, oxide or nitride $(\mathrm{U}+\mathrm{Pu}+\mathrm{Am}+\mathrm{Np})$
$0,1 \%$ (in mass)
Transmutation within the fuel
It is preferable to extract $\mathrm{Cm}$ for post-irradiation storage, returning $\mathrm{Pu}$ (fission
product of $\mathrm{Cm}$ ) to the reactor

The advantages of decentralized spent fuel reprocessing (within the SNFC) are:

1. No long-distance transportation, which allows to minimize the duration of all the stages of out-of-pile fuel cycle, making it last 1 year;

2. Increasing of nuclear fuel usage - power efficiency of fuel increases;

3. The closed fuel cycle can be constructed in such a way that fissile and radioactive materials never leave the NPP site - thus the safeguards measures become more reliant;

4. The reliability of nuclear fuel supply of the NPP increases because of its independence from some another fuel fabrication plant;

5. Decreasing of radiation environment near the NPP;

6. The fabrication ability of fuel power cycle units can be easily harmonized with necessary number of the constructed NPPs, just decreasing the necessary capital costs;
7. The complex of measures mentioned above can decrease RW reprocessing capital costs and make NPP economics more efficient.

Preliminary economic analysis showed that the capital costs of constructing nuclear fuel cycle on-site facilities of an NPP with two potential BREST-1200 commercial units are equal to approximately $15 \%$.

\section{Conclusion}

In Russia the scientific and technological foundation has been laid for both utilization of fast reactors and closing fuel cycles.

The experimental demonstration reactor unit is currently being constructed within the "PRORYV" Project. It consists of the BREST-OD-300 fast reactor unit, the fuel fabrication/refabrication unit and the spent fuel reprocessing unit. The utilization of this complex will result in creating the basis for the nuclear power industry of the new generation, 
which will be distinguished by:

1. Closing the fuel cycle on uranium and plutonium;

2. Inherent safety;

3. Approaching the principle of radiation equivalency when it comes to RW management;

4. Effective use of fresh raw materials;

5. Economic competitive performance.

\section{References}

[1] E. Adamov, L. Bolshov, I. Ganev, A. Zrodnikov, A. Kuznetsov, A. Lopatkin, A. Mastepanov, V. Orlov, V. Rachkov, V. Smirnov, M. Solonin, V. Uzhanova, N. Chernoplekov, G. Shatalov, White Paper of Nuclear Power, Publishing house of JSC N. A. Dollezhal Research and Development Institute of Power Engineering, Moscow, 2001 (in Russian).

[2] E. Adamov, I. Ganev, A. Lopatkin, et al., "Transmutation Fuel Cycle in Largescale Nuclear Power of Russia", Monograph, Publishing house of JSC N. A. Dollezhal Research and Development Institute of Power Engineering, Moscow, 1999 (in Russian).

[3] E. Muravyov, Relevance of Nuclear Fuel Cycle Closing, Nuclear Energy, volume 111, № 6, Moscow, 2011 (in Russian).

[4] E. Adamov, A. Dzhalavyan, A. Lopatkin, N. Molokanov, E. Muravyov, V. Orlov, S. Kalyakin, V. Rachkov, V. Troyanov, E. Avrorin, V. Ivanov, R. Aleksahin, Conceptual Issues of Nuclear Power Development Strategy in Russia in the $21^{\text {st }}$ Century, Nuclear Energy, volume 112, № 6, Moscow, 2012 (in Russian).
[5] M. Radchenko, A. Shadrin, P. Poluektov, O. Shmidt, A. Tuzov, Assimilation of a Closed Uranium-Plutonium Nuclear Fuel Cycle Based on Fast Reactors with Liquid-Metal Coolant, Nuclear Energy, volume 115, № 2, Moscow, 2013 (in Russian).

[6] V. Troyanov, A. Grachev, L. Zabudko, M. Skupov, Prospects for Using Nitride Fuel in Fast Reactors with a Closed Nuclear Fuel Cycle, Nuclear Energy, volume 117, № 2, Moscow, 2014 (in Russian).

[7] V. Troyanov, A. Grachev, L. Zabudko, M. Skupov, D. Zozulya, Program and Results of Reactor Tests of Mixed Nitride Fuel for Fast Reactors, Nuclear Energy, volume 118, № 2, Moscow, 2015 (in Russian).

[8] A. Grachev, L. Zabudko, A. Glushenkov, Yu. Ivanov, G. Kireev, M. Skupov, I. Gilmutdinov, P. Grin, E. Zvir, F. Kryukov, O. Nikitin, Research of Mixed Nitride Uranium-Plutonium Fuel within the Framework of «Proryv» Project, Nuclear Energy, volume 122, № 3, Moscow, 2017 (in Russian).

[9] IAEA Nuclear Energy Series No. NP-T-1.6. Liquid Metal Coolants for Fast Reactors Cooled by Sodium, Lead and Lead-Bismuth Eutectic, Vienna, 2012.

[10] A. Shadrin, V. Ivanov, M. Skupov, V. Troyanov, A. Zherebtsov, Comparison of Closed Nuclear Fuel Cycle Technologies, Nuclear Energy, volume 121, № 2, Moscow, 2016 (in Russian).

[11] A. Shadrin, K. Dvoeglazov, A. Maslennikov, V. Kashcheev, S. Tretyakova, O. Shmidt, V. Vidanov, O. Ustinov, V. Volk, S. Veselov, V. Ishunin, PH Process as a Technology for Reprocessing Mixed Uranium-Plutonium Fuel From BREST-OD-300 reactor, Radiochemistry, volume 58, № 3, Moscow, 2016 (in Russian). 